\title{
D. PERO GOMES BARROSO: TROVADOR SATIRICO
}

\author{
Affonso Robl \\ Universldade Federal do Paraná
}

\section{RESUMO}

O trovador pertencia à classe nobre. $O$ autor procura precisar, um pouco mais, os diferentes graus da nobreza medleval lusitana, na sua complexa estruturação: a família real, os acostados da corte, os ricos-homens, os infançōes, os cavaleiros e os escudeiros.

A seguir, examina, suscintamente embora, a vida e as cantigas satíricas do trovador português D. Pedro Gomes Barroso, ilustre ricome e privado de Fernando III e Afonso $x$, reis de Leão e Castela.

\section{TROVADORES}

Jograis e segreiis - que representavam a antiga cultura popular da Península, máxime da Galiza, - historicamente precedem os trovadores. Por volta do século $\mathrm{XI}$, surgiu na Provença uma espécie de aristocracia artistica, oriunda muitas vezes dos próprios jograis.Eram os trobadores (trobadors), que cantavam e tocavam nos saraus da nobreza. Fo. ram adquirindo os gostos e as maneiras cortesās, chegando a ser admitidos no convivio dos fidalgos. E da Occitânia vieram os trovadores ensinar à nobreza galaico-portuguesa "en maneira de proençal a fazer agora un cantar d'amor".

Prende-se a forma trobar, segundo teoria de Gaston Paris, a tropare, verbo decalcado sobre tropus. Este último termo se liga à sequentia e consistia numa ampliação musical e versificada que, desde o século VIII, costumava inserir-se num canto litúrgico de forma melismática. Tropare significava primeiro "fazer tropos" e, depois, "inventar ou compor um poema, uma melodia"; de trobar formou-se trobador, termo que, desde logo, passou a designar "o poeta 
compositor" e não o simples executante, pois a palavra referia-se expressamente ao ato da invenção artística. ${ }^{1}$

A princípio, conforme opinião de Hauser, os jograis precisaram improvisar e até meados do século XII foram, indubitavelmente, poetas e cantores ao mesmo tempo. Mais tarde, introduziu-se uma especialização: os trovadores criavam as cantigas, que grande parte dos jograis se limitava a recitar. Para cantar e divulgar suas composições, os trovadores mais ilustres recorriam aos serviços dos jograis assalariados. Surge, assim, uma divisāo do trabalho artístico, que, pelo menos no começo, definia com precisão a distân. cia entre o trovador e o jogral da plebe. ${ }^{2}$

Percebe-se entre as três categorias de artistas galegoportugueses a mesma gradação, hierarquia e estratificação que marcavam a sociedade peninsular da época: o trovador era fidalgo, o segrel era cavaleiro-vilão e o jogral não passava de simples vilão.

É certo que os trovadores pertenciam à nobreza. Mas, quais ordens ou categorias compreende a nobreza luso-galega? Pergunta dificil de ser respondida, pois as diferentes classes da sociedade medieval portuguesa, em sua complexa estruturação, carecem de monografias de base. Afora o contributo trazido pelas várias histórias gerais, não existem estudos pormenorizados sobre a nobreza, o clero ou o povo.

Monarcas houve que não desdenharam a arte de trovar; pelo contrário, tornaram-se mestres exímios na "gaia ciência", como D. Afonso X, de Leão e Castela, D. Sancho I e D. Dinis, reis de Portugal.

Pertenciam à primeira ordem da nobreza os acostados da casa real e os ricos-homens.

Acostados da corte eram os bastardos régios e os magnatas de velha cepa aparentados com a familia reinante, ou porque oriundos de infantas ilegitimas, ou porque casados com elas. Entre os trovadores que eram filhos de reis, mas havidos fora do casamento, figuram D. Afonso Sanches, D. Gil Sanches, D. Pedro de Portugal, conhecido com o título de Conde de Barcelos. Entre os aparentados com familias reais temos $D$. Abril Peres de Lumiares, o conde $D$. Gonçalo Garcia e D. Lopo Lias. ${ }^{3}$

Aristocratas de vetusta prosápia gótica ou franca, os ricomes - divites homines, no latim medieval, - eram poderosos senhores de vassalos e de honras e coutos, isto é,

1 Cf. Spina. Beglsmundo. A lírica troyadorcsca. 2. ed. Rlo de Janelro, Grifo, 1872. p. 140-2.

2 Cr, HaUser. Arnold. Historia social de la literatura y arte. 5. ed. Madrld, Gubdarrama, 1969. D. 293.

3 Ct. VAsConCELOS. Carolina Michaelds, Cartioneiro da Ajuda. Ed. crit. coment, Halle, M. Niemeyer, 1904. v. 2. D. 616. Abrevintura: CA. 
territórios privilegiados, isentos da tributação e fiscalização régias, e cujos titulares achavam-se investidos do direito jurisdicional. As honras eram consideradas imunes mercê da nobreza de seus senhores, ao passo que os coutos gozavam de imunidade mediante concessão do monarca. Importa observar que o termo ricome significava, propriamente, "homem que tem autoridade, poderoso", pois o étimo gótico reiks ou rich, elemento formador de muitos antropônimos, tem essa acepção. Os invasores da Península Ibérica no século $V$, que constituiam a nobreza de grado e de força, acumularam tantas posses, que o termo rico passou a desig. nar "o que possui muitos bens, opulento". Como privados e conselheiros do monarca, possuiam os ricos-homens a potestas de promulgar leis, conceder forais e confirmar todos os atos públicos. Convém lembrar que privado significava, primeiramente, "conselheiro mais intimo" e não, propria.. mente, "valido" (CBN. 888); porém, no segundo quartel do século XIV, a palavra já vinha assumindo o sentido de "favorito", como se depreende do sirventês do Conde de Barcelos contra Miguel Vivas, bispo eleito de Viseu, e contra Gomes Lourenço de Beja. Eram os ricos-homens que também ocupavam os mais altos cargos da cúria palaciana: alferes-mor (em latim signifer), chefe supremo da milícia, e mordomo-mor (maiordomus curiae), cargo mais importante da administraçāo civil; como tenentes, ficavam incumbidos da governança civil e militar das terras ou provincias.

Esses nobres de primeira grandeza usavam o título nobiliárquico de don. Provém este axionome do latim dominu > domno > donno > dono; por sua posição proclitica, dono reduziu-se a don. Alguns filólogos há que opinam que esse axionome provenha do vocativo domine $>$ domne $>$ donne. Assevera Grandgent: "En latin vulgar la forma de vocativo probablemente se perdió del todo, excepto tal vez en unas pocas frases hechas, como mi domine."4

Tinham os ricos-homens por insígnia pendão e caldeira, esta última símbolo de seu poder econômico. Afonso $\mathrm{X}$ caçoa de um dos seus ricomes que não se apresenta para 0 fossado" de maio, dizendo-lhe que "tragia pendon sen cal. deira" (CBN. 496), maneira original e irônica de dizer que andava faustosamente, mas deixava de pagar seus homens $\mathrm{E}$ em Alexandre Herculano, encontra-se este passo: "Por que nāo ides com os acostados que pelejam debaixo de vosso

4 GRandoent, C.H. Introducción al latin vulgar. 2. cd. Madrid, Revista de Flologla Románice. 1952. p. B1.

5 Fossado, do latim fossa. "cara, trincheira", desirasva, à época da Reconquista, as cxpedicóes as trinchetras da frontetra, a que estaiam obricados os rassalos; via de regra, realizavam-sc na primavera e duraram de sels semanas até tres meses. 
pendão e vivem da vossa caldeira, ajuntar-vos com o infante?":

Sem ciúvida, D. Afonso Lopes de Baiam, D. Fernāo Garcia Esgaravunha, D. João Peres de Aboim, D. João Soares Coelho, D. Pero Gomes Barroso, D. Vasco Gil foram, entre muitos outros, trovadores ricos-homens.

A segunda ordem da nobreza compreendia os infanções: "milites non infimis parentibus orti, sed nobiles genere necnon potestate - cavaleiros oriundos não de pais blebeus, mas nobres por nascimento e poderio". T Talvez se aplicasse este título aos filhos dos ricos-homens, reservando-se infante à prole régia. Infançon, do latim hispânico infantione, é o aumentativo, com certo ressaibo pejorativo (cf. escudeiron, citolon), de infante (lat. infans, "que não fala"). A partir do primeiro quartel do século XVI, o termo caiu em desuso, sendo substituído por filho d'algo e, depois, fidalgo.

Que os infanções eram inferiores aos ricos-homens claramente se deduz da lei de março de 1261, que, depois de fixar para o infanção uma comitiva menor que a do rico-homem, prescreve: " $\mathrm{E}$ aquel (isto é, o ricome) que tever de dous mil a fundo (que tiver dois mil maravedis) vaa assi como infançon".s $\mathbf{E}$ as cantigas d'escárnio e maldizer distinguem essas duas categorias de nobres. Joan Garcia de Guilhade, por exemplo, conta:

\section{"Vi eu estar noutro dia infanções con un ricome posfaçando de quen mal come" (CBN. 1503).}

Atesta a lei supra-mencionada que os infanções eram su. periores aos simples cavaleiros: "O cavaleiro que non for infançon non leve ao moesteiro nen aa eigreja que tres bestas e quatro homens".

Embora de ilustre ascendência, geralmente não gozavam, ao contrário dos ricos-homens, nem de poder, nem de senhorio. Reza A Partida II, I, 13: "E como quier que estas vengan antiguamente de buen linaje e ayan granaies credamientos, pero no son en cuenta destos grandes señores (os ricoshomens). $\mathbf{E}$ por ende non pueden nin deven usar de poder, nin de señorio, en las tierras que han, fueras ende en tanto quanto les fuere otorgado por los privilejos ae los empera-

7 Citado por BARROS, Henrique da Gama. História da administração püblica em Portugal nos séculos XII a XV, 2. ed, Lísboa, Sá da Costa. 1945-1947. v.4. p.360.

g BARRCS, D. 359

9 Citado em CA, D. 619. D. 4. 
dores e de los reys"." Também figuram pouco nos documentos legislativos, visto que quase nunca exerciam as mais altas funções públicas, pois, as mais das vezes, careciam de prestígio político ou econômico.

Carolina Michaëlis Vasconcelos é de opinião de que se devam incluir entre os infanções os trovadores Airas Peres Vuitorom, Fernão Rodrigues Redondo, Rodrigo Eanes Redondo e muitos outros. ${ }^{11}$

A terceira ordem da nobreza englobava os cavaleiros de linhagem. Uns, com pretensões a infançāo, tinha certo status e poderio: D. Lopo Lias trata o senhor de Lemos ora de infanção, ora de cavaleiro (CBN. 1340). Outros eram apenas donos de medianas posses, ou mesmo se encontravam reduzidos, pela inconstância da fortuna, a um só escudo e uma só lança. $\mathrm{E}$ preciso frisar que o sistema feudal, introduzido por influência francesa em época bastante tardia, provavelmente em tempos de Afonso III, não teve em Portugal condições de expandir-se como na Europa Central. Alem de outros, achamse no rol dos cavaleiros os trovadores Afonso Fernandes Cubel e Pero Goterres.

Finalmente, os escudeiros de origem fidalga compõem a quarta ordem da nobreza. Donzéis ou moços-pastores até aos quatorze anos e escudeiros em seguida, os filhos d'algo - de sangue nobre proveniente, ao menos, dos bisavós podiam ser armados cavaleiros, ao completar vinte e cinco anos. Fidalgos, porém, que cometessem ações indecorosas, ou fossem incapazes de sustentar cavalos e armas, eram rebaixados à vilania e a seus filhos era vedado, por desdouro no brasão ou escassez de fortuna, galgar ao grau de cavaleiro.

A sátira CBN. 1353 é desferida contra "un escudeiro que non era ben fidalgo e queria ser cavaleiro:

"Escudeiro, pois armas queredes, dized' ora con que comedes".

E Martin Soares escarnece de um escudeiro de pequeno logo, isto é, de condiçōes mesquinhas:
'Houv' Albardan caval' e seendeiro
e cuidava cavaleiro seer.
Quand' eu soub' estas novas primeiro, maravilhei-m' e non-no quis creer; fiz dereito, ca eu non vi fazer, des que nasci, d'albardan cavaleiro" (CBN. 1360)

- herculano, Alexandre. O bobo. 18. ed. Lisboa. bertrand, s.d. p.61. 
E certo que João de Gaia foi escudeiro, pois pospõe a seu nome esse título.

Em resumo, a classe dos trovadores era socialmente superior à dos segréis e jograis. Fidalgo que era, o trovador apresentava-se apenas a um público cortesão, e trobava e dizia son, se a voz o ajudasse, tão-somente por mero diletantismo.

Não obstante isso e embora os galego-portugueses lhes atribuíssem como funções citolar e dizer cantares alheios, jograis houve que, quando conseguiam por seu talento e cultura compor peças originais, pretendessem ser alçados à nobre categoria dos trovadores.

\section{PERO GOMES BARROSO}

Fidalgo português, da familia dos Guedãos, era este trovador filho bastardo de Gomes Viegas, senhor de Bastos, que de sua mulher legitima, Mor Rodrigues de Candarei, teve três filhos e de "u'a filha de u'u escudeiro, outro que non foi lídimo, que houve nome don Pero Gomes Barroso, que valeo mais que os outros irmãos, foi mui bõo e muito honrado", no dizer do autor do Quarto Livro de Linhagens."1

Sua condição de ilegítimo, aliada a um espirito aventureiro, levou-o, no segundo quartel do século XIII, a procurar melhor sorte fora de Portugal. Foi acolhido na corte de Fernando III, em Toledo. Lá, consorciando-se com Chamoa Fernandes, oriunda da ilustre família de D. Rodrigo de Trastamara, alcançou fortuna e notoriedade, mercê de suas qualidades de caráter. Entre os seus descendentes figura o chanceler Lopes de Ayala, o célebre cronista de Pedro o Cru.

Combateu ao lado do rei de Castela na tomada de Servilha, em novembro de 1248 , sendo um dos herdadores dessa cidade, conforme se depreende de uma de suas cantigas d'amigo. ${ }^{12}$

Fiel conselheiro de Afonso X, Gomes Barroso prestou-lhe relevantes serviços, tanto na luta contra a mourisma, como na reconciliação da nobreza rebelde, chegando mesmo a servir, em 1273, de mediador entre o Rei Sábio e os seus ricoshomens que se haviam aliado ao califa de Granada.

No Cancioneiro da Vaticana, sob o nome de Pero Gomes Barroso somente se encontram três cantigas d'amigo e um sirventês moral. Porém da autoria de Pero Barroso existem duas cantigas d'amor e sete cantigas d'escárnio e maldizer.

11 Citado dor NUNES. José Joanuin. Cantigas d'amigo dos trovadores galego-portugueses. Colmbra, Impr. Unveraldade de Colmbra, 1928. v. 1, p. 171, n. 1.

12 C1. NUNES, v. 2, n. CLXVII. 
Trata-se, ao que parece, de uma só pessoa, porquanto numa cantiga de maldizer, Pero Barroso fala da conquista da Andaluzia em termos tais, que dão a nitida impressão de que o autor tenha tomado parte ativa nessa guerra:

e con meu cavalo louro,
ben da vila da Grāada
tragu'eu o our' e o mouro" (LAPA 394). ${ }^{13}$

Esse maldizer é desferido contra Rui Gomes de Telha, outro português a serviço do rei de Castela, que queria apropriar-se indebitamente da glória de uma sortida, prenhe de prisioneiros e despojos, aos arredores de Granada; campanha que na realidade fora comandada pelo autor dessa cantiga. Em outra cantiga d'escárnio (LAPA 390), Barroso descreve a extrema penúria por que passou nos primeiros anos de sua carreira em Castela. Os amigos, vendo-o definhar, julgavam que se consumia de coita d'amor, que, além de outras coisas, faz que o apaixonado perca o apetite. Outro, porém, era 0 mal que 0 afligia a coita de comer: tinha vontade louca de comer um pedaço de pão, mas não tinha dinheiro para compróa-lo.

Ao lado de Afonso $\mathrm{X}$ e de Gil Peres Conde, moteja, de maneira bastante espirituosa, dos nobres, que, traidores ou covardes, abandonaram o monarca por ocasiāo das lutas contra os sarracenos da Andaluzia. Essa deserção dos vassalos vem confirmada na Crónica de Don Alfonso Décimo: "Muchos de las villas se excusban de lo servir por el llamamiento que les facia de cada año para la frontera, e en aquel tiempo iva cada un á servir três meses por lo que avia, ca el Rey non les daba nada de las fonsaderas". ${ }^{14}$

Um rico-homem, - que trazia alferes, pendão e tenda, leito e cobertor, cozinha, reposte (armário em que se guardava a baixela) e manjar, escançan (servo encarregado de servir o vinho), çaquiteiro (serviçal que distribuia os pães) e jograrete (pequeno jogral) - , apresentou-se fora do tempo usual do fossado, que se realizava em maio ou Pentecortes, não para combater, mas para se divertir. Contudo, para que ele não ficasse sem a insígnia da guerra que não experimentara, os cavaleiros assiduos aos combates ofereceram. lhe, por chacota, um ramo de maia da campanha do ano anterior (LAPA 391 e 393).

13 A abrevialura LAPA refere-se abra de LAPA. M.Rodriques. Cantigas d'cscarnho maldizer dos trovadores galogo-portugueses. 2. cd. Colmbra. Oslaxia, 1970. As Ictturss, de quando em quando. sío nossas.

Cltado dor LAPA, p. 3. 
Escarnece ainda de um rico-homem que se obstinava em nāo servir ao Rei Sábio na luta contra os infiéis. Apresentou-se, nuas em tempo de paz, para discutir com o soberano, que o ameaçava de confiscar-lhe os coutos. O refrảo dessa cantiga escarninha é de uma ironia bastante sutil, porém chistosa. O nobre reconhece que recebeu as terras que lhe haviam sido prometidas, mas lastima que o suserano nunca the dera oportunidade para servi-lo:

"Diz que ten terra qual pediu, mais, por que o nunca serviu, há mui gran querela del Rey" (LAPA 392).

Juntamente com Pedro Amigo de Sevilha, João Baveca e Gonçalo Eanes do Vinhal, foi Gomes Barroso um dos chufadores da pretensa peregrinação de Pero de Ambroa à Terra Santa (LAPA 395). Deve-se datar a polêmica contra os falsos cruzados pelo ano de 1269 , porquanto ela se prende à cruzada indicada por Jaime I de Aragão, pregada por um de seus filhos, D. Sancho, bispo de Toledo, e subvencionada em parte por Afonso $\mathrm{X}$. Nessa cruzada tomaram parte notáveis personalidades da época; entre elas, o nosso rico-homem trovador. ${ }^{\text {t5 }}$

Noutra ocasião, zomba amavelmente do impertinente e conhecido jogral Lourenço, que, sendo novo rico, nāo tinha experiência em investimentos. Havia comprado umas casas cujas paredes e teto estavam em péssimo estado e que não tinham nem cortinha (quintal), nem paaço (sala), nem cozinha:

$$
\begin{aligned}
& \text { “Pero Lourenço, comprastes } \\
& \text { uas casas e mercastes } \\
& \text { delas mal, pero catastes } \\
& \text { ant'as casas e, porén, } \\
& \text { par Deus, vós vos enganastes, } \\
& \text { que as non catastes ben. } \\
& \text { Se vós, come home dereito, } \\
& \text { as paredes e o teito } \\
& \text { catássedes, gran proveito } \\
& \text { vos houvera, a meu sén; } \\
& \text { vós sofred'end' o despeito, } \\
& \text { que as non catastes ben. }
\end{aligned}
$$

15 Cr. Marroni. Glovanna. Le poesic di Pedr'Amlgo de Sevilha. Annali. Soxione Romanza, Napoll, 10(2):307-8, jul. 1968. 
Pois non vistes i cortinha, nen paaço, nen cozinha, rependestes-vos aginha. Mais ora que prol vos ten? A pagar é a farinha, poi-las non catastes ben" (LAPA 389).

Enfim, o trovador D. Pedro Gomes Barroso explorou também os temas do "florebat olim" ou "laudatio temporis acti" e "ubi sunt", que o aproximam da temática do clérigo Martim Moxa:

"Do que sabia nulha ren non sei, polo mundo que vej' assi andar; e, quand' i cuido, hei log' a cuidar, per bõa fé, o que nunca cuidei: ca vej' agora o que nunca vi e ouço cousas que nunca oí.

Aqueste mundo, par Deus, non é tal qual eu vi outro, non há gran sazon; e por aquesto, no meu coraçon, aquel desej' e este quero mal, ca vej' agora o que nunca vi. e ouço cousas que nunca oi.

$E$ non receo mia morte por én, e, Deus lo sabe, queria morrer, ca non vejo de que haja prazer, nen sei amigo de que diga ben:

Ca vej' agora o que nunca vi e ouço cousas que nunca oí" (LAPA 388).

Esse sirventês moral, repassado de nostalgia dos bons tempos passados e de descrença nos maus tempos atuais, ainda hoje nos comove pela sinceridade, dorida e plangente, expressa sobretudo no belissimo refrão. 


\section{REFERENCIAS BIBLIOGRAFICAS}

1 BARRCS, Henrique da Gama. Hsitória da administração púhlica em Portugal nos séculos XII a XV. 2.ed. Lisboa, Sá da Costa, 1945-1947. v. 1.4.

2 GRANDGENT, C. H. Introducción al latín vulgar. 2. ed. Madrid, Revista de Filologia Románica, 1952.

3 HAUSER, Arnold. Historia social de la literatura y arte. 5. ed. Madrid, Guadarrama, 1969. 2 v.

4 HERCULANO, Alexandre. $O$ bobo. 18. ed. Lisboa, Bertrand, s. d.

5 LAPA, M. Rodrigucs. Cantigas d'escarnho e de maldizer dos cancioneiros medievais galego-portugueses. 2. ed. Colmbra, Galáxia, 1970.

6 MARroNI, Giovanna. Le poesie di Pedr'Amigo de Sevilha. Annali. Sezionc Romanza, Napolf, 10(2):189-339, jul. 1968.

7 NUNES, José Joaquim. Cantigas d'amigo dos trovadores galegoportugueses. Coimbra Smpr. Universidade de Coimbra, 1928. $3 \mathrm{v}$.

8 SPINA, Segismundo. A lirica trovadoresca. 2. ed. Rio de Janeiro, Grifo, 1972.

9 VASCONCELOS, Carollna Michaelis. Cancioneiro da Ajuda. Ed. crit. coment. Halle, M. Niemeyer, 1904. v. 2. 